\title{
Recent advances in understanding genetic variants associated with economically important traits in sheep (Ovis aries) revealed by high-throughput screening technologies
}

\author{
Song-Song XU ${ }^{1,2}$, Meng-Hua LI (凶) ${ }^{1}$ \\ 1 CAS Key Laboratory of Animal Ecology and Conservation Biology, Institute of Zoology, Chinese Academy of Sciences (CAS), \\ Beijing 100101, China \\ 2 University of Chinese Academy of Sciences, Beijing 100049, China
}

\begin{abstract}
Sheep are one of the most economically important domesticated animals for human society. However, genetic improvements for the key traits associated with meat, growth, milk, wool, reproduction, horns and tails progress slowly using conventional crossbreeding methods. With the development and utilization of highthroughput screening technologies over the last decade, a list of functional genes and genetic variants associated with these traits has been identified. This review covers recent genome-wide studies on sheep productive traits using high-throughput screening technologies, including those based on single-nucleotide polymorphisms and copy number variants at the whole-genome level (e.g., genome-wide association studies), transcriptome and DNA methylation sequences. Additionally, comprehensive information on functional genes and genetic variants associated with economically important traits in sheep is provided.
\end{abstract}

Keywords sheep, high-throughput screening, productive traits, genome-wide studies

\section{Introduction}

Sheep (Ovis aries) were one of the first animal species domesticated in the Fertile Crescent region $c .10000$ years ago. Following its domestication, a great variety of sheep breeds have been developed during the spread of sheep to other regions ${ }^{[1-3]}$. As an important part of the global animal industry, sheep provide meat, milk, wools and dietary fat sources for human society ${ }^{[4]}$. In particular, income for farmers in many countries with Islamic traditions comes from the sheep husbandry. However, as

Received December 31, 2016; accepted February 16, 2017

Correspondence: menghua.li@ioz.ac.cn the global population is expected to reach over nine billion people by 2050, highly efficient livestock production, including sheep, is needed to meet the expected demand ${ }^{[5]}$.

Over the past few decades, established breeding practices making use of the estimated breeding values from phenotypic and pedigree information have significantly improved the production efficiency of the sheep (e.g., the increase of milk yield) ${ }^{[6,7]}$. However, these approaches have been constrained, due to slow progress in genetic improvement and difficulty in separating desired from non-preferred traits ${ }^{[6-8]}$. To overcome such limitations, researchers have mapped quantitative trait loci (QTL) based on sparse microsatellite markers and identified candidate genomic regions for the targeted traits in sheep. However, the QTL mapping resolution has been quite low or coarse and the typical confidence interval of a given QTL usually covers a large genomic region of several mega-bases or even a whole chromosome. Therefore, it is unlikely that QTL mapping can detect the causal genes and variants, and reveal genetic mechanisms for the target traits in domestic animals like sheep ${ }^{[9]}$.

With the development and application of high-throughput screening technologies, genome-wide analyses of genetic variations has been shown to be an efficient strategy for identifying functional genes and genetic variants associated with economically important traits in sheep ${ }^{[10]}$. Whole-genome scale analyses are mainly used in genome-wide association studies (GWAS), selective sweep tests, RNA-seq, DNA methylation and copy number variations (CNVs) analysis. GWAS and selective sweep tests use mathematical approaches to pinpoint candidate causal genes and variants for relevant traits. RNA-seq has been explored to detect regulatory elements that are essential in expression of mRNA and microRNAs (i.e., miRNAs) related to target traits. DNA methylation analysis has been conducted to quantify the methylation of genes associated with particular traits. To date, these 
approaches have succeeded in revealing genes, genetic variants, signatures of selective sweeps and pathways associated with traits in sheep.

This review summarizes recent investigations that have revealed genetic mechanisms for economically important traits in sheep (i.e., meat, growth, milk, wool, reproduction, horns and tails) using high-throughput screening technologies (Table 1). Genetic variants, functional genes and pathways as well as the relevant technologies reviewed here will be useful for future genomics studies as well as omics-assisted breeding practices in sheep and other livestock.

\section{Genes and genetic variants associated with economically important traits in sheep}

\subsection{Meat and carcass traits}

Meat and carcass traits, including meat quality (e.g., muscle components, taste, tenderness and intramuscular fat content) and carcass weight are economically important in sheep. In recent years, several studies, particularly those using high-throughput screening technologies, have revealed a number of candidate genes and genetic variants associated with meat and carcass traits.

Although there have been only a small number of GWAS in sheep, many candidate genes related to meat and carcass traits have been identified, including lean meat yield (e.g., GDF8), marbling (e.g., ALDOA, FAM190A and $S T K 32 B)$, meat production and quality (e.g., $G H R$ ), fatty acid formation (e.g., ACACA, EVOLV6, FASN, MLXIPL and $S Y N R G$ ), (glycero) lipid biosynthesis (e.g., ACSL1, AGPAT9, ISYNA1 and SGK2) etc. ${ }^{[1-14]}$. Bolormaa et al., for example, performed a multi-trait GWAS using the Illumina Ovine SNP50 BeadChip in 10613 sheep, and found several candidate genes (e.g., APOL6, DLK1, $M E G 3, M E G 8$ and $M B$ ) on chromosomes 3, 6, 14, 18 and 21 for muscling, shear force, meat myoglobin content and fatty acid composition ${ }^{[15]}$. Also, Matika et al. identified multiple QTLs on chromosomes 1, 3, 6 and 24 using GWAS and the Illumina Ovine SNP50 BeadChip ${ }^{[16]}$. The QTLs contain several candidate genes (e.g., SPP1, $M E P E, I B S P, L C O R L$ and NCAPG) for bone-related traits and meat quality traits in sheep ${ }^{[16]}$.

Based on RNA-seq data at the transcriptome level, a large number of genes and miRNAs were revealed for meat and carcass traits, such as fat metabolism (e.g., NELL1, FMO3, AACS, ACACA, ACACB, ACOT6, ELOVL6, FASN, $H S D 17 B 12$ and $S C D$ ), muscle growth and development (e.g., HSPA6, ZIM3, SLC5A12, oar-miR-3955-5p, oarmiR-410-3p, bta-miR-183 and bta-miR-182) etc. ${ }^{[17-20]}$. In an integrated analysis of miRNAs and mRNA expression profiles from a high-throughput screening study, 36 novel and six known miRNAs (e.g., miR-10 and miR-let-7 families) and a few candidate genes (e.g., FGF1,
$I G F 2 B P 2, I G F-2$ and $T C F 4$ ) relevant to cell development and cell differentiation were detected ${ }^{[21]}$. In addition, 463 differentially expressed genes including $M R F s, G X P 1$ and $S T A C 3$ related to muscle growth and development were identified by an RNA-seq study ${ }^{[22]}$.

With the advent of next generation sequencing technology, studies using whole genome DNA methylation from various developmental stages (e.g., embryogenesis, genomic imprinting, $\mathrm{X}$-inactivation and tumorigenesis) of livestock, have been performed ${ }^{[74]}$. However, currently there are only two such studies for meat and carcass traits in sheep. In longissimus dorsi muscle of sheep, Couldrey et al. found a number of annotated genes with different levels of DNA methylation ${ }^{[23]}$. Cao et al. identified 399 different methylated regions and found two DNA methylation $\mathrm{CpG}$ sites in the LTBP1 gene, whose RNA expression was significantly involved in skeletal muscle development ${ }^{[24]}$.

\subsection{Growth traits}

Growth traits of sheep include weight at various ages, average daily gain and bone traits (e.g., weight and area). These traits have been under long-term directional selection with moderate genetic control ${ }^{[75]}$. Over past decades, a number of QTLs have been detected for growth traits in sheep. Recently, GWAS and selective sweep tests have been widely used to detect candidate genes for growth traits in sheep, which could increase the efficiency of artificial breeding and selection. These genes include $N P R 2, H M G A 2$ and $B M P 2$ associated with skeletal morphology and body size, and those (e.g., GRM1, POL, $M B D 5, U B R 2, R P L 7$ and $S M C 2$ ) affecting post-weaning gain and accounting for body growth (e.g., GHR and $A N K S 1 B)^{[11,25-27]}$. Meanwhile, a number of genetic variants and signaling pathways have also been identified in these studies. Gholizadeh et al. performed a GWAS for growth traits in Baluchi sheep using the Illumina Ovine SNP50 BeadChip and detected candidate genes associated with weight at various ages ${ }^{[28]}$. For example, STRBP and TRAMIL1 affected bodyweight at the 53 and 83 week stages; DAAMI and APIP had a central role in controlling weaning weight; PHF15, PRSS12 and MAN1A1 genes were involved in the six-month-weight; SYNE1, WAPAL and $D A A M 1$ genes were associated with the yearling weight ${ }^{[28]}$. Also, Matika et al. conducted a GWAS using the Illumina Ovine SNP50 BeadChip, and identified a QTL on chromosome 6 , surrounded by a number of genes (e.g., $O S T / S P P 1, M E P E, I B S P, N C A P G$ and $L C O R L)$ affecting bone traits ${ }^{[16]}$. By comparative genomic analyses of 77 native sheep using whole-genome sequences, Yang et al. detected several genes (e.g., GPX3, FSTL1, PVR, EXT2, ALT4, SOX6, HAND2, PDGFD and BMPR2) and signaling pathways (HIF-1, VSMC and GH/IGF-1) associated with body size in various environments ${ }^{[29]}$. 
Table 1 Summary of high-throughput screening studies on economically important traits in sheep

\begin{tabular}{|c|c|c|c|}
\hline Trait & Approach & Genes, miRNAs and signaling pathways & References \\
\hline \multirow[t]{3}{*}{ Meat and carcass } & GWAS & $\begin{array}{l}\text { Lean meat yield: } G D F 8 \\
\text { Marbling: } A L D O A, S T K 32 B \text { and } F A M 190 A \\
\text { Meat myoglobin content and fatty acid composition: FASN, MLXIPL, EVOLV6, ACACA, } \\
\text { SYNRG, APOL6, MB, ACSL1, ISYNA1, SGK2 and } A G P A T 9 \\
\text { Meat production and quality: } G H R \\
\text { Muscling and shear force: } M E G 3, M E G 8 \text { and } D L K 1\end{array}$ & [11-16] \\
\hline & RNA-seq & $\begin{array}{l}\text { Fat metabolism:NELL1, FMO3, AACS, ACACA, ACACB, ACOT6, ELOVL6, FASN, } \\
\text { HSD17B12 and SCD } \\
\text { Muscle growth and development: HSPA6, ZIM3, SLC5A12, FGF1, IGF2BP2, IGF-2, } \\
T C F 4, M R F s, \text { GXP1 and STAC3; and miRNAs miR-10, miR-let-7 family, oar-miR-3955- } \\
\text { 5p, oar-miR-410-3p, bta-miR-183 and bta-miR-182 }\end{array}$ & {$[17-22]$} \\
\hline & DNA methylation & Muscle development: 399 different methylated regions and $L T B P 1$ & {$[23,24]$} \\
\hline Growth & $\begin{array}{l}\text { GWAS and selective } \\
\text { sweeps }\end{array}$ & $\begin{array}{l}\text { Body size: NPR2, HMGA2, BMP2, GPX3, FSTL1, PVR, EXT2, ALT4, SOX6, HAND2, } \\
P D G F D, B M P R 2, G H R, A N K S 1 B \text {; and Signal pathways HIF-1, VSMC and GH/IGF-1 } \\
\text { Post-weaning gain: GRM1, POL, MBD5, UBR2, RPL7, SMC2, DAAM1 and APIP } \\
\text { Bodyweight: GSTRBP, TRAMIL1, PHF15, PRSS12, MAN1A1, SYNE1, WAPAL, } \\
\text { DAAM1, OST/SPP1, MEPE, IBSP, NCAPG and LCORL } \\
\text { Bone-related traits: SPP1, MEPE, IBSP, LCORL and NCAPG }\end{array}$ & {$[11,16,25-29]$} \\
\hline \multirow[t]{2}{*}{ Wool } & $\begin{array}{l}\text { GWAS and selective } \\
\text { sweeps }\end{array}$ & $\begin{array}{l}\text { Coat pigmentation: KIT, ASIP, KITLG, EDN3, MITF, MCIR, HERC2-like, TYRP1, ASIP } \\
\text { and MITF } \\
\text { Growing wing hairs: FRY } \\
\text { Wool fiber diameter: TSPEAR, PIK3R4, KRTCAP3, YWHAZ and CCNY } \\
\text { Fiber diameter coefficient of variation and fineness dispersion: gKIF16B } \\
\text { Crimp: PTPN3, TCF9, GPRC5A,DDX47, EPHA5, TPTE2 and NBEA }\end{array}$ & {$[11,27,30-36]$} \\
\hline & RNA-seq & $\begin{array}{l}\text { Hair/fleece development and function: KRTs, KRTAPs families, CST3, CSTB, S100A11, } \\
\text { PPARD, CSTA, SIVA1, CCDC85B, FOXE1, VAX2, BAK1, ADRA1B, PKIA and HNF4A } \\
\text { Coat color regulation: DCT, MATP, TYR and TYRP1 } \\
\text { Fiber diameter: GNPAT, LPIN2, CHKA, PLD2, PLA2G3, SMPD2, UGCG, PIP4K2A, } \\
\text { ACOT8, SLC25A17, NCOR1, FABP6, HSD11B1, STAR, FABP4 and SLC25A20 } \\
\text { Follicle bulb regression and regeneration: Wnt, Jak-STAT, MAPK, Notch, TGF- } \beta \text {, Toll- } \\
\text { like receptor and VEGF pathways } \\
\text { Telogen hair follicles development and growth: } 1910 \text { known miRNAs and } 2261 \text { novel } \\
\text { mature miRNAs }\end{array}$ & {$[37-41]$} \\
\hline \multirow[t]{2}{*}{ Milk } & $\begin{array}{l}\text { GWAS and selective } \\
\text { sweeps }\end{array}$ & $\begin{array}{l}\text { Milk protein and fat contents: } L A L B A \\
\text { Milk production performances: } P A L M D \text { and } R F P 145 \\
\text { Milk production traits: } A B C G 2, S P P 1, S C D \text { and } S O C S 2, P K D 2, M E P E \text { and } I B S P\end{array}$ & {$[34,42-44]$} \\
\hline & RNA-seq & $\begin{array}{l}\text { Higher cheese yield: } C S N 2, C S N 3 \text { and } L A L B A \\
\text { Lipid metabolism: } B T N 1 A 1, X D H, F A S N, A D F P, S C D, H-F A B P \text { and } A C S S 2 \\
\text { High protein production: } F A B P 4, S U C N R 1, H S P 70 \text { and } H S P B 8 \\
\text { Milk secretion: } 2764 \text { genes }\end{array}$ & {$[45-48]$} \\
\hline \multirow[t]{3}{*}{ Reproduction } & $\begin{array}{l}\text { GWAS and selective } \\
\text { sweeps }\end{array}$ & $\begin{array}{l}\text { Mammalian reproduction: } P R L P \\
\text { Metabolic regulation and reproduction: } T S H R \\
\text { Increased ovulation rate/litter size: } G D F 9 \text { and } B M P 15 \\
\text { Oocyte development: } C C N B 2 \text { and } S L C 8 A 3 \\
\text { Pre-weaning gain: } P O L, R P L 7, M S L 1 \text { and } S H I S A 9\end{array}$ & {$[11,13,49-52]$} \\
\hline & RNA-seq & $\begin{array}{l}\text { Fecundity: BAX, BAD, NDUFA13, CAV1, LOC101117112, PAX8,IFI6, PRLR, PGR, } \\
\text { ESR2, CYP19A1, CYP11A1, HSD17B12, INHBA, BMPR1B and BMPR2 receptors; and } \\
\text { miRNAs oar-miR-665-5p, oar-miR-411a-5p, oar-miR-1197-3p and oar-miR-134-3p } \\
\text { Fecundity and prolificacy: signaling pathways } W n t, M A P K, G \text {-protein, } T G F-\beta \text { and } P P A R\end{array}$ & [53-57] \\
\hline & DNA methylation & $\begin{array}{l}\text { Reproductive traits: } A D I P O Q, A B C G 1, B R W D 1, G R I N 2 B, M E T T L 6, S I A H 2, S L C O 2 A 1 \text {, } \\
T N I K \text { and } U M O D L 1\end{array}$ & {$[58]$} \\
\hline Horn & $\begin{array}{l}\text { GWAS and selective } \\
\text { sweeps }\end{array}$ & Horn development: $R X F P 2, M T X 2, H O X$ clusters, $E V X 2$ and $K I A A 1715$ & {$[11,27,32-34,59-68]$} \\
\hline \multirow[t]{2}{*}{ Tail } & Selective sweeps & $\begin{array}{l}\text { Fat deposition or tail morphology: PPP2CA, SKP1, TCF7, RXFP2, PPP1CC, PDGFD, } \\
B M P 2, V N R T, P P A R A, R X R A, K L F 11, H O X A 11, B M P 2, P P P 1 C C, S P 3, S P 9, W D R 92, \\
\text { PROKR1 and ETAA1 }\end{array}$ & {$[34,69-72]$} \\
\hline & RNA-seq & $\begin{array}{l}\text { Lipid metabolism: NELL1, FMO3, ACACA, ELOVL6, HSD17B12, CYP11A1, GDE1, } \\
A C A C B, A C O T 6, F A S N, S C D \text { and } A C O T 2 \text {; and miRNAs bta-miR-18a, hsa-miR-29b-1- } \\
5 p, \text { ssc-miR-22-3p, and hsa-miR-4749-5p }\end{array}$ & {$[17,18,20,73]$} \\
\hline
\end{tabular}




\subsection{Wool traits}

As one of the most important animals used to provide fibers to the textile industry, sheep breeding for wool traits has focused mainly on fiber diameter, fiber diameter coefficient of variation, fineness dispersion, staple length and crimp, shedding, color and hair follicles. Compared to other farm animals, the genetic basis underlying wool traits in sheep has been given greater attention for many years $^{[37]}$. Understanding the genetic mechanisms of wool traits would be helpful for sheep breeding as well as for elucidating the genetic basis of hair development in humans. In recent years, many candidate genes and genetic variants affecting wool traits have been reported.

GWAS provides a powerful approach for identifying candidate genes for wool traits. However, to date, only a small number of GWAS have been conducted for wool traits in sheep. A number of CNVs associated with wool fiber were identified using the Ovine Infinium HD SNP BeadChip ${ }^{[76]}$. Based on GWAS in sheep, it is concluded that KIT, ASIP, KITLG, EDN3, MITF, MC1R and HERC2like genes are related to coat pigmentation, and the $F R Y$ gene is involved in the growth of wing hairs ${ }^{[11,27,30-34]}$. By using GWAS coupled with genome-wide scan for selective signatures, $\mathrm{Li}$ et al. identified three pigmentation candidate genes (i.e., TYRP1, ASIP and MITF) and ASIP gene, which might explain the color difference between pigmented and unpigmented wool in Finnsheep ${ }^{[35]}$. Wang et al. also performed a GWAS in Chinese Merino sheep populations using the Illumina Ovine SNP50 BeadChip, and found that TSPEAR, PIK3R4, KRTCAP3, YWHAZ and CCNY genes are associated with wool fiber diameter ${ }^{[36]}$. In addition, the KIF16B gene could be associated with fiber diameter coefficient of variation and fineness dispersion, and PTPN3, TCF9, GPRC5A, DDX47, EPHA5, TPTE2 and $N B E A$ genes were related to crimp ${ }^{[36]}$.

RNA-seq analyses have also been performed to characterize candidate genes and genetic variants that affect wool traits in sheep. Moreover, miRNAs and signaling pathways have also been identified for these traits. For example, several miRNAs (e.g., oar-miR-103$3 p$, oar-miR-148b-3p, oar-miR-320-3p, oar-miR-31-5p, oar-novel-1-5p, oar-novel-2-3p, miR-let-7, miR-199 and $m i R-200$ families) were found to affect wool follicle development, and a large number of genes (e.g., KRTS, KRTAPS families, CST3, CSTB, S100A11, PPARD, CSTA, SIVA1, CCDC85B, FOXE1, VAX2, BAK1, ADRA1B, $P K I A$ and $H N F 4 A$ ) were shown to be related to hair/ fleece development. In addition, earlier investigations indicated that several genes (e.g., DCT, MATP, TYR and $T Y R P 1)$ played a central roles in coat color regulation and a few signaling pathways (Wnt, Jak-STAT, MAPK, Notch, TGF- $\beta$, Toll-like receptor and VEGF) were involved in the regulation of wool follicle bulb regression and regeneration ${ }^{[38-41]}$. Using Solexa sequencing (Illumina Genome Analyzer), Li et al. identified 1910 known and
2261 novel mature miRNAs, and these miRNAs could have essential roles in telogen hair follicle development and growth, which are important for improving wool quality $^{[77]}$. Furthermore, $\mathrm{Fu}$ et al. sequenced the skin transcriptome and identified genes associated with wool diameter $^{[37]}$. Some early reported genes (e.g., GNPAT, LPIN2, CHKA, PLD2, PLA2G3, SMPD2, UGCG, PIP4K2A, ACOT8, SLC25A17, NCOR1, FABP6, HSD11B1, STAR, FABP4 and SLC25A20) in lipids and lipoproteins metabolic pathways are significantly related to the variation of fiber diameter ${ }^{[37]}$.

\subsection{Milk traits}

Sheep milk is an important source of revenue, accounting for a large portion of global milk production and is commonly used to produce many cultured dairy products, such as cheese. Milk traits can be determined by measuring yield, protein, fat and lactose percentage. Since sheep milk is mainly produced by multi-purpose local breeds with low-to-medium milk yields, globally few sheep breeds have been developed specifically for milk production ${ }^{[78]}$. Recently, functional genes affecting milk production have been identified using high-throughput screening technologies.

To data only a few investigations involving GWAS and selective sweep tests have been conducted to identify genomic regions influencing milk traits in sheep. GarcíaGámez et al. reported the first GWAS for milk traits using a high-throughput SNP array and identified the most likely candidate gene (i.e., $L A L B A$ ) affecting milk protein and fat contents in dairy sheep ${ }^{[79]}$. Moioli et al. presented the first genome-wide characterization of selective sweeps in dairy sheep and detected nine candidate regions harboring a couple of genes (e.g., PALMD and RFP145) related to the milk production performance ${ }^{[42]}$. Moreover, other strong candidate genes (e.g., $A B C G 2, S P P 1, S C D, S O C S 2$, $P K D 2, M E P E$ and $I B S P$ ) associated with milk production traits have been proposed using selective sweep and $\operatorname{GWAS}^{[34,43,44]}$.

Recently, RNA-seq has also been applied in a genomic study on milk traits in sheep. A set of candidate genes related to milk traits were identified, including CSN2, $C S N 3$ and $L A L B A$ genes associated with higher cheese yield; BTN1A1, XDH, FASN, ADFP, SCD, H-FABP, $A C S S 2$ genes involved in lipid metabolism; and FABP4, $S U C N R 1, H S P 70, H S P B 8$ genes with a potential crucial role in high protein production ${ }^{[45-47]}$. By comparing gene expression in milk somatic cells by RNA-seq in the same sheep before and after linseed feeding, Giordani et al. found 2764 genes potentially regulating milk secretion ${ }^{[48]}$.

\subsection{Reproductive traits}

Reproductive traits, especially those related to number of births, litter size and pre-weaning viability, are critical for 
sheep production ${ }^{[80]}$. Reproductive traits typically have low heritability, thus genetic improvement of these trait has been limited to the long-lasting established breeding approaches ${ }^{[81,82]}$ and marker-assisted selection provides an excellent opportunity for improving these traits ${ }^{[83]}$.

To date, a set of genes and QTLs affecting these traits in sheep were reported by GWAS. For example, the prolactin receptor gene was reported as a key regulator of mammalian reproduction, thyroid stimulating hormone receptor as having a pivotal role in metabolic regulation and control of reproduction, and growth differentiation factor $9(G D F 9)$ as a strong candidate gene for increased ovulation rate/litter size ${ }^{[11,49-51]}$. Moreover, an X-chromosomal locus close to the BMP15 gene was identified in highly prolific and normal ewes by GWAS, and two novel mutations in the BMP15 gene were found to be associated with increased litter size and ovulation rate, resulting in an atypically high prolificacy ${ }^{[52]}$. It is also found that two genes (CCNB2 and SLC8A3) are associated with oocyte development and four genes (POL, RPL7, MSL1 and SHISA9) could affect pre-weaning gain via GWAS ${ }^{[13]}$.

It is well known that miRNAs have important generegulatory roles in reproductive traits. Using genome-wide sequencing of mRNAs and miRNAs, many candidate genes, miRNAs and signaling pathways regulating sheep fecundity have been obtained. In a genome-wide transcriptome analysis of different breeds with high- and lowfecundity sheep, multiple candidate genes, such as $B A X$, BAD, NDUFA13, CAV1, LOC101117112, PAX8 and IFI6; and miRNAs, such as oar-miR-665-5p, oar-miR-411a-5p, oar-miR-1197-3p and oar-miR-134-3p, were shown to be critical for sheep fecundity, and signaling pathways $W n t$, $M A P K$ and G-protein were shown to be potentially critical for regulating sheep fecundity and prolificacy ${ }^{[53-55]}$. Furthermore, an RNA-seq study with multiple sheep breeds revealed that PRLR, PGR, ESR2, CYP19A1, $C Y P 11 A 1, H S D 17 B 12$, INHBA, and BMP receptors $(B M P R 1 B$ and $B M P R 2)$ genes could be involved in follicular development or control of ovulation, and $T G F-\beta$ and PPAR pathways might regulate female reproduction $^{[56,57]}$.

Methylated-DNA immunoprecipitation sequencing has also been employed to identify genes for phenotypic traits in domestic animals. To data, there has only been one study reported using this method ${ }^{[58]}$. In that study, 19 single nucleotide variations and nine candidate genes (ADIPOQ, ABCG1, BRWD1, GRIN2B, METTL6, SIAH2, SLCO2A1, $T N I K$ and $U M O D L 1$ ) were identified as being related to sheep reproductive traits.

\subsection{Horn traits}

As a cranial appendage in sheep, horns are important in accessing resources and mates, although they might not be desired in livestock farming and breeding. For example, horned males are inclined to attack other animals or people ${ }^{[84,85]}$. Thus, hornless (or polled) individuals are bred for animal welfare and economic reasons. It has been shown that horn traits of sheep, such as size, number and shape, are controlled by several autosomal loci ${ }^{[59]}$.

From 2011 to 2015, several genes (e.g., RXFP2, MTX2 and $H O X$ gene clusters) and QTLs affecting horn development on chromosome 10 were identified in multiple sheep breeds ${ }^{[1,27,32-34,59-65]}$. On chromosome 2, a genomic region of $132.0-133.1 \mathrm{Mb}$ that contains the HOXD gene cluster and EVX2 and KIAA1715 genes was identified using GWAS ${ }^{[66]}$. These genes are related to the formation of limbs and genital buds ${ }^{[66]}$. A similar genomic region (131.9-132.6 Mb) on chromosome 2 is associated with the four-horn phenotype, and MTX2 and HOXD cluster within this region were revealed to be involved in horn ontogenesis ${ }^{[67]}$. In Damara sheep, HOXD was located also on chromosome 2 by a GWAS study on horn number, and HOXD was shown to be critical in embryonic development of appendages ${ }^{[68]}$.

\subsection{Tail traits}

Domestic sheep can be classified into fat- and thin-tailed breeds. Nowadays a variety of feed sources can be provided in hostile environments, thus fat tails are less important as an energy reserve ${ }^{[86]}$. Moreover, fat-tailed sheep require more feed, which increases the cost of production. Therefore, thin-tailed sheep are preferred for sheep farming. Revealing the molecular mechanisms of fat deposition in sheep tails could provide valuable information for sheep breeding practices.

However, only a handful of studies on sheep tail traits have been conducted by selective sweep test. Moradi et al. presented the first genome-wide characterization of selective sweeps for thin- and fat-tailed sheep, and revealed QTLs containing candidate genes (e.g., PPP2CA, SKP1 and TCF7) on chromosomes 5, 7 and $X^{[69]}$. Through population structure and selection tests using whole-genome SNPs, Wei et al. detected three strong selective genomic windows containing two functional genes, PPPICC and PDGFD, which could be associated with the phenotypic differences of tail types, i.e., thin versus fat tails ${ }^{[34]}$. Moioli et al. performed a genome-wide scan using approximately $50000 \mathrm{SNP}$, and detected $B M P 2$ and $V N R T$ genes related to fat deposition in sheep tails ${ }^{[70]}$. Through a genome-wide high-density SNP study of sheep with three tail types, Zhu et al. detected several regions with CNVs harboring functional genes associated with fat deposition, such as PPARA, RXRA and KLF11 ${ }^{[71]}$. Furthermore, Yuan et al. applied selection tests based on 50K SNP genotype data, and showed that HOXA11, BMP2, PPP1CC, SP3, SP9, WDR92, PROKR1 and ETAA1 genes may be involved in the formation of fat tails in sheep $^{[72]}$. 
RNA-seq studies have also been carried out to reveal the genetic basis of fat deposition in sheep tails. By comparing transcriptome data of fat-tailed (Kazakh sheep) and shorttailed sheep (Tibetan sheep), Wang et al. demonstrated that NELL1 and FMO3 genes are involved in fat metabolism and deposition of adipose tissues ${ }^{[17]}$. Multiple genes (e.g., $A C A C A$, ELOVL6, HSD17B12, CYP11A1, GDE1, $A C A C B, A C O T 6, F A S N, S C D$ and ACOT2) and miRNAs (e.g., bta-miR-18a, hsa-miR-29b-1-5p, ssc-miR-22-3p and $h s a-m i R-4749-5 p$ ) were also shown to be essential in regulation of lipid metabolism in sheep with different tail morphologies ${ }^{[18,20]}$. By comparing transcriptomes of liver tissues between Mongolian and Lanzhou fat-tailed sheep with different tail types, Cheng et al. detected seven differentially expressed genes (four upregulated and three downregulated) using RNA-seq ${ }^{[73]}$.

\section{Conclusions and perspectives}

Recently data on whole-genome genetic variations and genome sequences have contributed greatly to the under- standing of genetic mechanisms underlying a variety of phenotypic traits in sheep. Genomic resources also provide a basis for genetic improvements of economically important traits in sheep. Identification of functional genes and variants associated with these traits helps facilitate traditional breeding techniques using quantitative approaches and molecular breeding techniques are costeffective and time-saving compared to conventional crossbreeding schemes.

It should be mentioned that a large number of candidate genes and miRNAs associated with the target traits require further functional verification (Fig. 1). Currently, the use of large genomic and epi-genomic data sets from highthroughput sequencing is to some extent limited by current computational and statistical approaches. Therefore, novel tools that integrate multiple levels of omics data, and system biology analysis, will be required in the postgenomic era. We believe that integrated analyses of genomes, epi-genomes, transcriptomes and proteomics on a genome-wide scale will provide novel insights into genetic mechanisms underlying these important traits in sheep.

\section{Box 1: Workflow of identification, validation and application of candidate function genes or variants}

For example, bone morphogenetic protein receptor 1B $(B M P R 1 B)$ encodes a member of the bone morphogenetic protein $(B M P)$ receptor family of transmembrane serine/threonine kinases that belongs to the transforming growth factor $\beta$ (TGF$\beta$ ) receptor family. Through QTL fine mapping and deep-sequencing approaches, $B M P R 1 B$ has been demonstrated to be a strong candidate gene for the prolificacy traits in sheep ${ }^{[7,87,88]}$. Also, BMPR1B knockout mice showed irregular estrous cycles and an impaired pseudo-pregnancy response; meanwhile, the level of mRNA for cyclooxygenase 2, an enzyme required for cumulus expansion, was increased ${ }^{[89]}$. In addition, a non-conservative substitution in the coding sequence of the $B M P R 1 B$ was found by expression level difference between genotypes to be closely associated with the hyper-prolific phenotype of ewe ${ }^{[90]}$. Therefore, $B M P R 1 B$ has a promising application in marker-assisted in breeding programs for prolific sheep (Fig. 1).

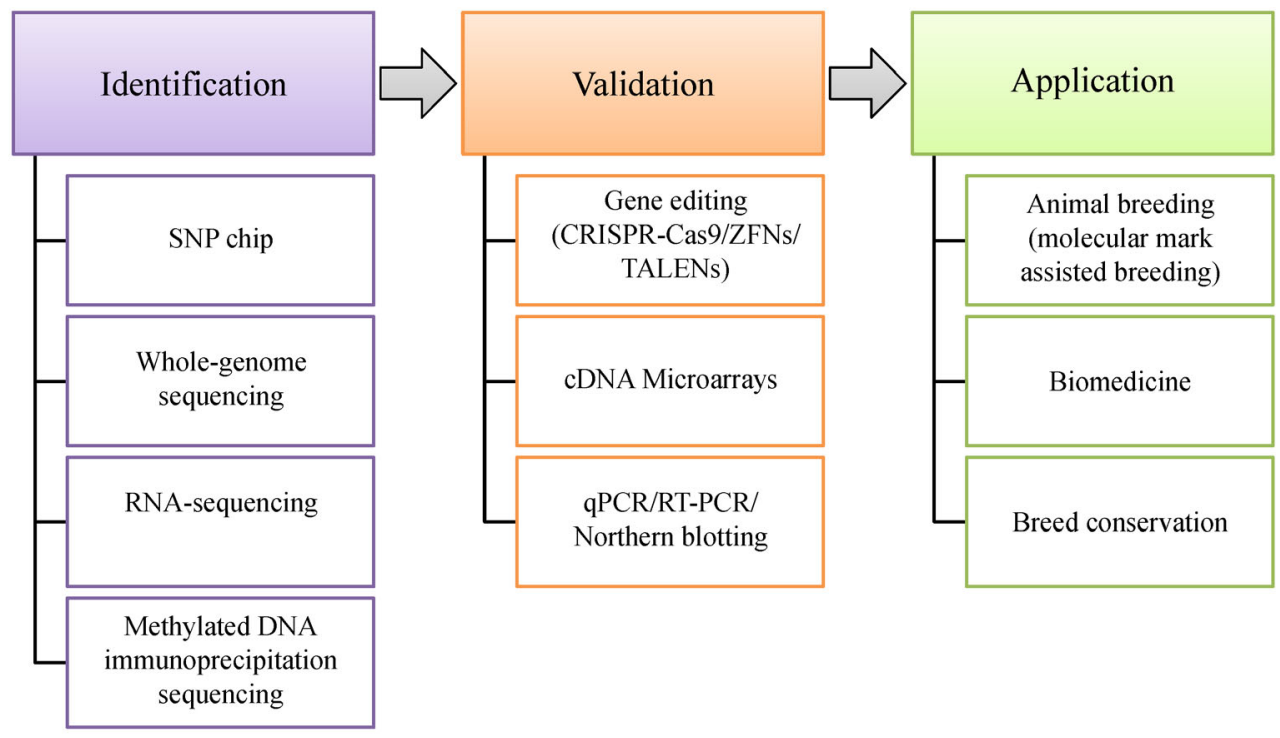

Fig. 1 Workflow of identification, validation and application of candidate function genes or variants 
Acknowledgements This work was financially supported by the National Natural Science Foundation of China (31272413, 3161101336), the National Transgenic Breeding Project of China (2014ZX0800952B), the External Cooperation Program of Chinese Academy of Sciences (152111KYSB20150010) and the Taishan Scholars Program of Shandong Province (201511085).

Compliance with ethics guidelines Song-Song $\mathrm{Xu}$ and Meng-Hua $\mathrm{Li}$ declare that they have no conflicts of interest or financial conflicts to disclose.

This article is a review and does not contain any studies with human or animal subjects performed by any of the authors.

\section{References}

1. Larson G, Piperno D R, Allaby R G, Purugganan M D, Andersson L, Arroyo-Kalin M, Barton L, Climer Vigueira C, Denham T, Dobney K, Doust A N, Gepts P, Gilbert M T P, Gremillion K J, Lucas L, Lukens L, Marshall F B, Olsen K M, Pires J C, Richerson P J, Rubio de Casas R, Sanjur O I, Thomas M G, Fuller D Q. Current perspectives and the future of domestication studies. Proceedings of the National Academy of Sciences of the United States of America, 2014, 111(17): 6139-6146

2. Gorkhali N A, Dong K Z, Yang M, Song S, Kader A, Shrestha B S, He X H, Zhao Q J, Pu Y B, Li X C, Kijas J, Guan W J, Han J L, Jiang L, Ma Y H. Genomic analysis identified a potential novel molecular mechanism for high-altitude adaptation in sheep at the Himalayas. Scientific Reports, 2016, 6(1): 29963

3. Lv F H, Peng W F, Yang J, Zhao Y X, Li W R, Liu M J, Ma Y H, Zhao Q J, Yang G L, Wang F, Li J Q, Liu Y G, Shen Z Q, Zhao S G, Hehua E E, Gorkhali N A, Farhad Vahidi S M, Muladno M, Naqvi A N, Tabell J, Iso-Touru T, Bruford M W, Kantanen J, Han J L, Li M $\mathrm{H}$. Mitogenomic meta-analysis identifies two phases of migration in the history of Eastern Eurasian Sheep. Molecular Biology and Evolution, 2015, 32(10): 2515-2533

4. Safari E, Fogarty N M, Gilmour A R. A review of genetic parameter estimates for wool, growth, meat and reproduction traits in sheep. Livestock Production Science, 2005, 92(3): 271-289

5. Thornton P K. Livestock production: recent trends, future prospects. Philosophical Transactions of the Royal Society B: Biological Sciences, 2010, 365(1554): 2853-2867

6. Niemann H, Kues W A. Application of transgenesis in livestock for agriculture and biomedicine. Animal Reproduction Science, 2003, 79(3-4): 291-317

7. Goddard M E, Hayes B J. Mapping genes for complex traits in domestic animals and their use in breeding programmes. Nature Reviews Genetics, 2009, 10(6): 381-391

8. Wang S H, Zhang K, Dai Y P. Advances in genetic engineering of domestic animals. Frontiers of Agricultural Science \& Engineering, 2016, 3(1): 1-10

9. Zhang H, Wang Z P, Wang S Z, Li H. Progress of genome wide association study in domestic animals. Journal of Animal Science and Biotechnology, 2012, 3(1): 26

10. Jiang Y, Xie M, Chen W B, Talbot R, Maddox J F, Faraut T, Wu C H, Muzny D M, Li Y X, Zhang W G, Stanton J A, Brauning R, Barris W C, Hourlier T, Aken B L, Searle S M J, Adelson D L, Bian
C, Cam G R, Chen Y L, Cheng S F, DeSilva U, Dixen K, Dong Y, Fan G Y, Franklin I R, Fu S Y, Fuentes-Utrilla P, Guan R, Highland M A, Holder M E, Huang G D, Ingham A B, Jhangiani S N, Kalra D, Kovar C L, Lee S L, Liu W Q, Liu X, Lu C X, Lv T, Mathew T, McWilliam S, Menzies M, Pan S K, Robelin D, Servin B, Townley D, Wang W L, Wei B, White S N, Yang X H, Ye C, Yue Y J, Zeng P, Zhou Q, Hansen J B, Kristiansen K, Gibbs R A, Flicek P, Warkup C C, Jones H E, Oddy V H, Nicholas F W, McEwan J C, Kijas J W, Wang J, Worley K C, Archibald A L, Cockett N, Xu X, Wang W, Dalrymple B P. The sheep genome illuminates biology of the rumen and lipid metabolism. Science, 2014, 344(6188): 1168-1173

11. Kijas J W, Lenstra J A, Hayes B, Boitard S, Porto Neto L R, San Cristobal M, Servin B, McCulloch R, Whan V, Gietzen K, Paiva S, Barendse W, Ciani E, Raadsma H, McEwan J, Dalrymple B. Genome-wide analysis of the world's sheep breeds reveals high levels of historic mixture and strong recent selection. PLoS Biology, 2012, 10(2): e1001258

12. Johnson P L, Van Stijn T C, Henry H, McLean N J, Lee M. Genome wide association study using the ovine SNP50 BeadChip and lambs selected for extremes for carcass lean meat yield. Association for the Advancement of Animal Breeding and Genetics, 2013, 20: 495498

13. Wang H H, Zhang L, Cao J X, Wu M M, Ma X M, Liu Z, Liu R Z, Zhao F P, Wei C H, Du L X. Genome-Wide Specific Selection in Three Domestic Sheep Breeds. PLoS ONE, 2015, 10(6): e0128688

14. Bolormaa S, van der Werf J H J, Hayes B J, Goddard M E, Daetwyler H D. Pleiotropic multi-trait genome-wide association reveals putative candidate genes for fatty acid composition in Australian sheep. Association for the Advancement of Animal Breeding and Genetics, 2015, 21: 49-52

15. Bolormaa S, Hayes B J, van der Werf J H J, Pethick D, Goddard M E, Daetwyler H D. Detailed phenotyping identifies genes with pleiotropic effects on body composition. BMC Genomics, 2016, 17 (1): 224

16. Matika O, Riggio V, Anselme-Moizan M, Law A S, Pong-Wong R, Archibald A L, Bishop S C. Genome-wide association reveals QTL for growth, bone and in vivo carcass traits as assessed by computed tomography in Scottish Blackface lambs. Genetics, Selection, Evolution, 2016, 48(1): 11

17. Wang X L, Zhou G X, Xu X C, Geng R Q, Zhou J P, Yang Y X, Yang Z X, Chen Y L. Transcriptome profile analysis of adipose tissues from fat and short-tailed sheep. Gene, 2014, 549(2): 252-257

18. Miao X Y, Luo Q M, Qin X Y, Guo Y T. Genome-wide analysis of microRNAs identifies the lipid metabolism pathway to be a defining factor in adipose tissue from different sheep. Scientific Reports, 2015, 5(1): 18470

19. Miao X, Luo Q, Qin X. Genome-wide analysis reveals the differential regulations of mRNAs and miRNAs in Dorset and Small Tail Han sheep muscles. Gene, 2015, 562(2): 188-196

20. Miao X Y, Luo Q M, Qin X Y, Guo Y T, Zhao H J. Genome-wide mRNA-seq profiling reveals predominant down-regulation of lipid metabolic processes in adipose tissues of Small Tail Han than Dorset sheep. Biochemical and Biophysical Research Communications, 2015, 467(2): 413-420

21. Lv X Y, Sun W, Yin J F, Ni R, Su R, Wang Q Z, Gao W, Bao J J, Yu $\mathrm{J}$ R, Wang L H, Chen L. An integrated analysis of microRNA and 
mRNA expression profiles to identify RNA expression signatures in Lambskin Hair Follicles in Hu Sheep. PLoS ONE, 2016, 11(7): e 0157463

22. Sun L M, Bai M, Xiang L J, Zhang G S, Ma W, Jiang H Z. Comparative transcriptome profiling of longissimus muscle tissues from Qianhua Mutton Merino and Small Tail Han sheep. Scientific Reports, 2016, 6(1): 33586

23. Couldrey C, Brauning R, Bracegirdle J, Maclean P, Henderson H V, McEwan J C. Genome-wide DNA methylation patterns and transcription analysis in sheep muscle. PLoS ONE, 2014, 9(7): e101853

24. Cao J X, Wei C H, Liu D M, Wang H H, Wu M M, Xie Z Y, Capellini T D, Zhang L, Zhao F P, Li L, Zhong T, Wang L J, Lu J, Liu R Z, Zhang S F, Du Y F, Zhang H P, Du L X. DNA methylation landscape of body size variation in sheep. Scientific Reports, 2015, 5 (1): 13950

25. Riggio V, Matika O, Pong-Wong R, Stear M J, Bishop S C. Genome-wide association and regional heritability mapping to identify loci underlying variation in nematode resistance and body weight in Scottish Blackface lambs. Heredity, 2013, 110(5): 420 429

26. Zhang L, Liu J S, Zhao F P, Ren H X, Xu L Y, Lu J, Zhang S F, Zhang X N, Wei C H, Lu G B, Zheng Y M, Du L X. Genome-wide association studies for growth and meat production traits in sheep. PLoS ONE, 2013, 8(6): e66569

27. Zhang L F, Mousel M R, Wu X L, Michal J J, Zhou X, Ding B, Dodson M V, El-Halawany N K, Lewis G S, Jiang Z. Genome-wide genetic diversity and differentially selected regions among Suffolk, Rambouillet, Columbia, Polypay, and Targhee sheep. PLOS ONE, 2013, 8(6): e65942

28. Gholizadeh M, Rahimi-Mianji G, Nejati-Javaremi A. Genomewide association study of body weight traits in Baluchi sheep. Journal of Genetics, 2015, 94(1): 143-146

29. Yang J, Li W R, Lv F H, He S G, Tian S L, Peng W F, Sun Y W, Zhao Y X, Tu X L, Zhang M, Xie X L, Wang Y T, Li J Q, Liu Y G, Shen Z Q, Wang F, Liu G J, Lu H F, Kantanen J, Han J L, Li M H, Liu M J. Whole-genome sequencing of native sheep provides insights into rapid adaptations to extreme environments. Molecular Biology and Evolution, 2016, 33(10): 2576-2592

30. Kijas J W, Serrano M, McCulloch R, Li Y, Salces Ortiz J, Calvo J H, Pérez-Guzmán M D. Genome-wide association for a dominant pigmentation gene in sheep. Journal of Animal Breeding and Genetics, 2013, 130(6): 468-475

31. Yang G L, Fu D L, Lang X, Wang Y T, Cheng S R, Fang S L, Luo Y Z. Mutations in MC1R gene determine black coat color phenotype in Chinese sheep. Scientific World Journal, 2013, 2013(5): 675382

32. Fariello M I, Servin B, Tosser-Klopp G, Rupp R, Moreno C, Cristobal M S, Boitard S. Selection signatures in worldwide sheep populations. PLoS ONE, 2014, 9(8): e103813

33. Al-Mamun H A, Clark S A, Kwan P, Gondro C. Genome-wide linkage disequilibrium and genetic diversity in five populations of Australian domestic sheep. Genetics, Selection, Evolution, 2015, 47 (1): 90

34. Wei C H, Wang H H, Liu G, Wu M M, Cao J X V, Liu Z, Liu R Z, Zhao F P, Zhang L, Lu J, Liu C S, Du L X. Genome-wide analysis reveals population structure and selection in Chinese indigenous sheep breeds. BMC Genomics, 2015, 16(1): 194

35. Li M H, Tiirikka T, Kantanen J. A genome-wide scan study identifies a single nucleotide substitution in ASIP associated with white versus non-white coat-colour variation in sheep (Ovis aries). Heredity, 2014, 112(2): 122-131

36. Wang Z P, Zhang H, Yang H, Wang S Z, Rong E G, Pei W Y, Li H, Wang N. Genome-wide association study for wool production traits in a Chinese Merino sheep population. PLoS ONE, 2014, 9(9): e107101

37. Fu S Y, Qi Y X, He X L, Da L, Wang B, Rigele T E, Wu J H, Yang D, Liu Y B, Zhang W G. Transcriptome analysis reveals skin lipid metabolism related to wool diameter in sheep. BioRxiv, 2016. doi: $10.1101 / 051359$ (preprint)

38. Liu G B, Liu R Z, Li Q Q, Tang X H, Yu M, Li X Y, Cao J H, Zhao S $\mathrm{H}$. Identification of microRNAs in wool follicles during anagen, catagen, and telogen phases in Tibetan sheep. PLoS One, 2013, 8 (10): e77801

39. Fan R W, Xie J S, Bai J M, Wang H D, Tian X, Bai R, Jia X Y, Yang L, Song Y F, Herrid M, Gao W J, He X Y, Yao J B, Smith G W, Dong C S. Skin transcriptome profiles associated with coat color in sheep. BMC Genomics, 2013, 14(1): 389

40. Yue Y J, Liu J B, Yang M, Han J L, Guo T T, Guo J, Feng R L, Yang B H. De novo assembly and characterization of skin transcriptome using RNAseq in sheep (Ovis aries). Genetics and Molecular Research, 2015, 14(1): 1371-1384

41. Liu G B, Liu R Z, Tang X H, Cao J H, Zhao S H, Yu M. Expression profiling reveals genes involved in the regulation of wool follicle bulb regression and regeneration in sheep. International Journal of Molecular Sciences, 2015, 16(5): 9152-9166

42. Moioli B, Scata M C, Steri R, Napolitano F, Catillo G. Signatures of selection identify loci associated with milk yield in sheep. $B M C$ Genetics, 2013, 14(1): 76

43. Gutiérrez-Gil B, Arranz J J, Pong-Wong R, Garcia-Gamez E, Kijas J, Wiener P. Application of selection mapping to identify genomic regions associated with dairy production in sheep. PLOS ONE, 2014, 9(5): e94623

44. Rupp R, Senin P, Sarry J, Allain C, Tasca C, Ligat L, Portes D, Woloszyn F, Bouchez O, Tabouret G, Lebastard M, Caubet C, Foucras G, Tosser-Klopp G. A point mutation in suppressor of cytokine signalling 2 (Socs2) increases the susceptibility to inflammation of the mammary gland while associated with higher body weight and size and higher milk production in a sheep model. PLoS Genetics, 2015, 11(12): e1005629

45. Suárez-Vega A, Gutierrez-Gil B, Klopp C, Robert-Granie C, TosserKlopp G, Arranz J J. Characterization and comparative analysis of the milk transcriptome in two dairy sheep breeds using RNA sequencing. Scientific Reports, 2015, 5(1): 18399

46. Suárez-Vega A, Gutierrez-Gil B, Klopp C, Tosser-Klopp G, Arranz J J. Comprehensive RNA-Seq profiling to evaluate lactating sheep mammary gland transcriptome. Scientific Data, 2016, 3: 160051

47. Suárez-Vega A, Gutierrez-Gil B, Arranz J J. Transcriptome expression analysis of candidate milk genes affecting cheese-related traits in 2 sheep breeds. Journal of Dairy Science, 2016, 99(8): 6381-6390

48. Giordani T, Vangelisti A, Conte G, Serra A, Natali L, Ranieri A, Mele M, Cavallini A. Transcript profiling in the milk of dairy ewes 
fed extruded linseed. Genomics Data, 2017, 11: 17-19

49. Våge D I, Husdal M, Kent M P, Klemetsdal G, Boman I A. A missense mutation in growth differentiation factor 9 (GDF9) is strongly associated with litter size in sheep. BMC Genetics, 2013, 14 (1): 1

50. Gholizadeh M, Rahimi-Mianji G, Nejati-Javaremi A, De Koning D J, Jonas E. Genome-wide association study to detect QTL for twinning rate in Baluchi sheep. Journal of Genetics, 2014, 93(2): 489-493

51. Lv F H, Agha S, Kantanen J, Colli L, Stucki S, Kijas J W, Joost S, Li M H, Ajmone Marsan P. Adaptations to climate-mediated selective pressures in sheep. Molecular Biology and Evolution, 2014, 31(12): 3324-3343

52. Demars J, Fabre S, Sarry J, Rossetti R, Gilbert H, Persani L, TosserKlopp G, Mulsant P, Nowak Z, Drobik W, Martyniuk E, Bodin L. Genome-wide association studies identify two novel BMP15 mutations responsible for an atypical hyperprolificacy phenotype in sheep. PLoS Genetics, 2013, 9(4): e1003482

53. Miao X, Luo Q. Genome-wide transcriptome analysis between small-tail Han sheep and the Surabaya fur sheep using highthroughput RNA sequencing. Reproduction, 2013, 145(6): 587-596

54. Miao X, Qin Q L X. Genome-wide transcriptome analysis of mRNAs and microRNAs in Dorset and Small Tail Han sheep to explore the regulation of fecundity. Molecular and Cellular Endocrinology, 2015, 402: 32-42

55. Miao X Y, Luo Q M, Zhao H J, Qin X Y. Ovarian transcriptomic study reveals the differential regulation of miRNAs and lncRNAs related to fecundity in different sheep. Scientific Reports, 2016, 6(1): 35299

56. Chen H Y, Shen H, Jia B, Zhang Y S, Wang X H, Zeng X C. Differential gene expression in ovaries of Qira black sheep and Hetian sheep using RNA-Seq technique. PLoS ONE, 2015, 10(3): e0120170

57. Hu X J, Pokharel K, Peippo J, Ghanem N, Zhaboyev I, Kantanen J, $\mathrm{Li} \mathrm{M} \mathrm{H}$. Identification and characterization of miRNAs in the ovaries of a highly prolific sheep breed. Animal Genetics, 2016, 47 (2): 234-239

58. Cao J X, Wei C H, Zhang S Z, Capellini T D, Zhang L, Zhao F P, Li L, Zhong T, Wang L J, Du L X, Zhang H P. Screening of reproduction-related single-nucleotide variations from MeDIP-seq data in sheep. Molecular Reproduction and Development, 2016, 83 (11): 958-967

59. Wiedemar N, Drögemüller C A. 1.8-kb insertion in the $3^{\prime}-\mathrm{UTR}$ of RXFP2 is associated with polledness in sheep. Animal Genetics, 2015, 46(4): 457-461

60. Johnston S E, McEwan J C, Pickering N K, Kijas J W, Beraldi D, Pilkington J G, Pemberton J M, Slate J. Genome-wide association mapping identifies the genetic basis of discrete and quantitative variation in sexual weaponry in a wild sheep population. Molecular Ecology, 2011, 20(12): 2555-2566

61. Dominik S, Henshall J M, Hayes B J. A single nucleotide polymorphism on chromosome 10 is highly predictive for the polled phenotype in Australian Merino sheep. Animal Genetics, 2012, 43(4): 468-470

62. Poissant J, Davis C S, Malenfant R M, Hogg J T, Coltman D W. QTL mapping for sexually dimorphic fitness-related traits in wild bighorn sheep. Heredity, 2012, 108(3): 256-263

63. Kijas J W, Miller J E, Hadfield T, McCulloch R, Garcia-Gamez E, Porto Neto L R, Cockett N. Tracking the emergence of a new breed using 49,034 SNP in sheep. PLoS ONE, 2012, 7(7): e41508

64. Randhawa I A S, Khatkar M S, Thomson P C, Raadsma H W. Composite selection signals can localize the trait specific genomic regions in multi-breed populations of cattle and sheep. BMC Genetics, 2014, 15(1): 34

65. Kijas J W, Naumova A K. Haplotype-based analysis of selective sweeps in sheep. Genome, 2014, 57(8): 433-437

66. Ren X, Yang G L, Peng W F, Zhao Y X, Zhang M, Chen Z H, Wu F A, Kantanen J, Shen M, Li M H. A genome-wide association study identifies a genomic region for the polycerate phenotype in sheep (Ovis aries). Scientific Reports, 2016, 6(1): 21111

67. Kijas J W, Hadfield T, Sanchez M N, Cockett N. Genome-wide association reveals the locus responsible for four-horned ruminant. Animal Genetics, 2016, 47(2): 258-262

68. Greyvenstein O F C, Reich C M, van Marle-Koster E, Riley D G, Hayes B J. Polyceraty (multi-horns) in Damara sheep maps to ovine chromosome 2. Animal Genetics, 2016, 47(2): 263-266

69. Moradi M H, Nejati-Javaremi A, Moradi-Shahrbabak M, Dodds K G, McEwan J C. Genomic scan of selective sweeps in thin and fat tail sheep breeds for identifying of candidate regions associated with fat deposition. BMC Genetics, 2012, 13(1): 10

70. Moioli B, Pilla F, Ciani E. Signatures of selection identify loci associated with fat tail in sheep. Journal of Animal Science, 2015, 93 (10): 4660-4669

71. Zhu C Y, Fan H Y, Yuan Z H, Hu S J, Ma X M, Xuan J L, Wang H W, Zhang L, Wei C H, Zhang Q, Zhao F P, Du L X. Genome-wide detection of CNVs in Chinese indigenous sheep with different types of tails using ovine high-density 600K SNP arrays. Scientific Reports, 2016, 6(1): 27822

72. Yuan Z, Liu E, Liu Z, Kijas J W, Zhu C, Hu S, Ma X, Zhang L, Du L, Wang H, Wei C. Selection signature analysis reveals genes associated with tail type in Chinese indigenous sheep. Animal Genetics, 2017, 48(1): 55-66

73. Cheng X, Zhao S G, Yue Y, Liu Z, Li H W, Wu J P. Comparative analysis of the liver tissue transcriptomes of Mongolian and Lanzhou fat-tailed sheep. Genetics and Molecular Research, 2016, 15(2): 15028572

74. Li N, Ye M Z, Li Y R, Yan Z X, Butcher L M, Sun J H, Han X, Chen Q A, Zhang X Q, Wang J. Whole genome DNA methylation analysis based on high throughput sequencing technology. Methods, 2010, 52(3): 203-212

75. Safari E, Fogarty N M, Gilmour A R. A review of genetic parameter estimates for wool, growth, meat and reproduction traits in sheep. Livestock Production Science, 2005, 92(3): 271-289

76. Tian Y, Huang X, Tian K, Di J, Bai Y, Xu X, Fu X, Wu W, Shi X, Zhao B. Identification of copy number variations in fine wool sheep using Ovine SNP600 BeadChip array. Journal of Animal Science, 2016, 94(7): 29-30

77. Li J P, Qu H E, Jiang H Z, Zhao Z H, Zhang Q L. Transcriptomewide comparative analysis of microRNA profiles in the telogen skins of Liaoning Cashmere goats (Capra hircus) and Fine-Wool sheep (Ovis aries) by Solexa Deep Sequencing. DNA and Cell Biology, 2016, 35(11): 696-705 
78. Ida A, Vicovan P G, Radu R, Vicovan A, Cutova N, Enciu A. Improving the milk production at the breeds and populations of sheep from various geo-climatic zones. Lucrări Științifice-Universitatea De Științe Agricole Si Medicină Veterinară, 2012, 57: 34-38

79. Garcia-Gamez E, Gutierrez-Gil B, Sahana G, Sanchez J P, Bayon Y, Arranz J J. GWA analysis for milk production traits in dairy sheep and genetic support for a QTN influencing milk protein percentage in the LALBA gene. PLoS ONE, 2012, 7(10): e47782

80. Abdoli R, Zamani P, Mirhoseini S Z, Ghavi Hossein-Zadeh N, Nadri S. A review on prolificacy genes in sheep. Reproduction in Domestic Animals, 2016, 51(5): 631-637

81. Notter D R. Genetic aspects of reproduction in sheep. Reproduction in Domestic Animals, 2008, 43(2): 122-128

82. Liu Q Y, Pan Z Y, Wang X Y, Hu W P, Di R, Yao Y X, Chu M X. Progress on major genes for high fecundity in ewes. Frontiers of Agricultural Science and Engineering, 2014, 1(4): 282-290

83. Abdoli R, Zamani P, Deljou A, Rezvan H. Association of BMPR-1B and $G D F 9$ genes polymorphisms and secondary protein structure changes with reproduction traits in Mehraban ewes. Gene, 2013, 524(2): 296-303

84. Johnston S E, Gratten J, Berenos C, Pilkington J G, Clutton-Brock T H, Pemberton J M, Slate J. Life history trade-offs at a single locus maintain sexually selected genetic variation. Nature, 2013, 502 (7469): 93-95

85. Martin A M, Festa-Bianchet M, Coltman D W, Pelletier F. Sexually antagonistic association between paternal phenotype and offspring viability reinforces total selection on a sexually selected trait. Biology Letters, 2014, 10(2): 104-111

86. Nejati-Javaremi A, Izadi F, Rahmati G, Moradi M, Izadi F. Selection in fat-tailed sheep based on two traits of fat-tail and body weight versus single-trait total body weight. International Journal of Agriculture and Biology, 2007, (4): 645-648

87. Peng W Z, Xu J, Zhang Y, Feng J X, Dong C J, Jiang L K, Feng J Y, Chen B H, Gong Y W, Chen L, Xu P. An ultra-high density linkage map and QTL mapping for sex and growth-related traits of common carp (Cyprinus carpio). Scientific Reports, 2016, 6(1): 26693

88. Gholizadeh M, Rahimi-Mianji G, Nejati-Javaremi A, De Koning D J, Jonas E. Genome wide association study to detect QTL for twinning rate in Baluchi sheep. Journal of Genetics, 2014, 93(2): 489-493

89. Yi S E, LaPolt P S, Yoon B S, Chen J Y C, Lu J K H, Lyons K M. The type I BMP receptor BMPRIB is essential for female reproductive function. Proceedings of the National Academy of Sciences of the United States of America, 2001, 98(14): 79947999

90. Mulsant P, Lecerf F, Fabre S, Schibler L, Monget P, Lanneluc I, Pisselet C, Riquet J, Monniaux D, Callebaut I, Cribiu E, Thimonier J, Teyssier J, Bodin L, Cognie Y, Chitour N, Elsen J M. Mutation in bone morphogenetic protein receptor-IB is associated with increased ovulation rate in Booroola Merino ewes. Proceedings of the National Academy of Sciences of the United States of America, 2001, 98(9): 5104-5109 